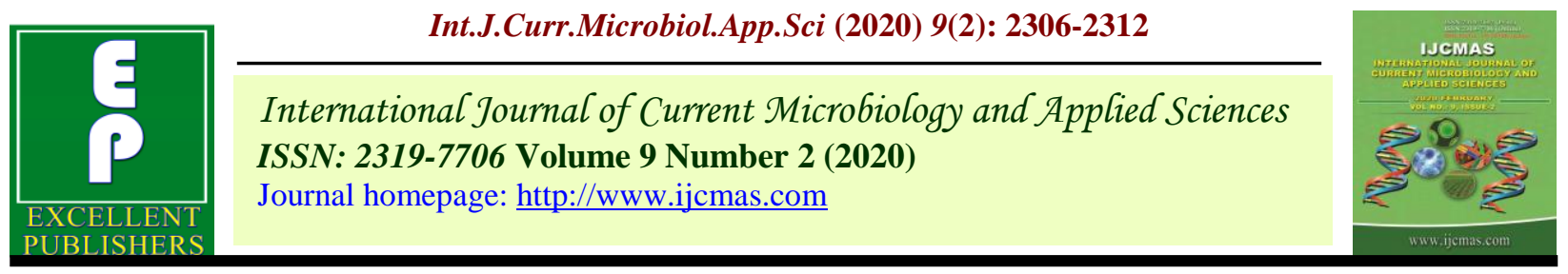

Original Research Article

https://doi.org/10.20546/ijcmas.2020.902.261

\title{
Prediction of Rice Water Requirement Using FAO-CROPWAT-8.0 Model in Dehradun, Uttarakhand, India
}

\author{
Vikash Singh* and Ramesh Verma
}

Department of Farm Engg. I.Ag.Sc., Banaras Hindu University, Varanasi-221005, U.P, India

*Corresponding author

Keywords

FAO-CROPWAT-

8.0, Evapo-

transpiration,

Effective Rainfall

Article Info

Accepted:

15 January 2020

Available Online:

10 February 2020
A B S T R A C T

Insufficient water supply is one of the most important factor governing agricultural productions. In addition to rainfall, a thorough knowledge of seasonal values of evaporation and crop transpiration, runoff, deep drainage and soil water storage is required to estimate the water need of crop. Water management is crucial to rightly offer and economize on water use in improvement of rice productivity. This paper aims to estimate Rice water requirement and irrigation water requirement in Dehradun district, based on the New Loc-Clim projected meteorological data. Rice water requirements are estimated by using crop coefficient approach. Reference evapotranspiration are calculated by FAO Penman-Monteith method. Moreover, the irrigation water requirements are simulated by calibrated CROPWAT-8.0 model using the meteorological parameters.

\section{Introduction}

Water demand has been growing rapidly due to population growth and increasing living standards and as a result, water shortage has become serious problem which have made it necessary to improve integrated technology and multidisciplinary water resources management capabilities. Proper water management practices are the need of the day to enhance food production while save water as much possible or in other words to increase water use efficiency of field crops. Besides the increasing demand of water for other purposes (industry and domestic use), degradation of water quality will also limit the water availability for agriculture sector in the coming future (FAO, 56). So the only tool to overcome this phenomenon is enhancing the water use efficiency, it is also usually termed as water productivity. In many countries, particularly in India, water for agriculture is becoming increasingly scarce and serious water shortages are developing in the light of growing water demands from different sectors (IWMI 2010). Agriculture is the largest (81\%) consumer of water (an essential input for crop production) and hence more efficient use of 
water in agriculture needs to be top most priority in India (Surendran et al., 2013). For the accurate planning and delivery of the necessary amount of the water in the time and space can conserve water. A scarce water resources and growing competitions for water will reduce its availability for irrigation. Achieving greater efficiency of water use will be a primary challenge for the near future and will include the employment of techniques and practices that deliver a more accurate supply of water to crops. Prediction of the crop water requirement is of vital importance in water resources management. Crop water requirements are normally expressed by the rate of evapotranspiration (ET) in $\mathrm{mm} \mathrm{day}^{-1}$ or $\mathrm{mm}$ period $^{-1}$. One of the major practices adopted by the researchers for estimating water requirement of crops is modelling. For determination of crop evapotranspiration and yield responses to water, CROPWAT-8.0 model is used which was developed by the FAO Land and Water Development Division (FAO 1992). It includes a simple water balance model that allows the simulation of crop water stress conditions and estimation of yield reductions based on well-established methodologies. Several researchers have used the model for analyzing crop water requirements in different parts of the world (Kar and Verma, 2005; Martyniak et al., 2006; Dechmi et al., 2003). The irrigation schedule recommendations for various crops should be location-specific, considering the soil types and agro-ecological conditions.

\section{Materials and Methods}

\section{Study Area}

Dehradun is one of the districts of Uttarakhand State of India. The district, located at $30.19^{\circ} \mathrm{N}$ latitude and $78.04^{\circ} \mathrm{E}$ longitude, comes under West Himalayan Region (I) with the cultivated area of $49.9^{*} 10^{3}$ ha, as per the classification of Agro- climatic zone by planning commission. The average normal annual rainfall of this area is about $2065.7 \mathrm{~mm}$. The location map of the study area has been shown in fig 1 .

\section{Crop data}

The major field crops in study area are Rice, Wheat, Barley, Maize, Arhar, Gram, Lentil, etc., fruit crops are: Apple, Pear, Peach, Plum, Apricot, Walnut, Citrus, Walnut, Mango, Litchi, Aonla and Guava. In this research for estimating the irrigation water requirement, the guidelines of Ministry of Irrigation, G.O.I and FAO, has been followed for using the salient details of crops considered for the study.

\section{Metrological data}

Metrological data given in Table 1, 2 and Figure 2.

\section{CROPWAT-8.0 Model}

The Model is a freeware for the calculation of crop water requirements based on soil, climate and crop data and existing or new irrigation climate data and crop needs (Doorenbos and Pruitt, 1976, 1977). In addition, the program allows the development of irrigation schedules for different management conditions and the calculation of the supply system of the variety of cropping patterns. The model really helps irrigation engineers to analyze the use of crop water of an irrigation system with the different culture and can provide data that are essential for the design of channel. CROPWAT-8.0 can also be used to evaluate farmers' irrigation practices and to estimate crop performance under both rain fed and irrigated conditions (Adriana and Cuculeanu, 1999). All procedures of calculation in CROPWAT-8.0 are based on the two FAO publications of the Irrigation and Drainage Series, namely, No. 
56 "Crop Evapotranspiration - Guidelines for computing crop water requirements" and No. 33 titled "Yield response to water".

\section{Reference evapotranspiration}

This parameter was calculated in CROPWAT-8.0 Model which uses the FAO Penman-Monteith method (Allen et al., 1998). In this model, most of the equation parameters are directly measured or can be readily calculated from weather data.

$$
\mathrm{ET}_{0}=\frac{0.408 \Delta\left(R_{\mathrm{n}}-G\right)+\gamma \frac{900}{T+273} u_{2}\left(\mathrm{e}_{\mathrm{s}}-\mathrm{e}_{\mathrm{a}}\right)}{\Delta+\gamma\left(1+0.34 \mathrm{u}_{2}\right)}
$$

Where, $\mathrm{ET}_{\mathrm{o}}$ is reference evapotranspiration $\left(\mathrm{mm}\right.$ day $\left.^{-1}\right), \mathrm{R}_{\mathrm{n}}$ is net radiation at the crop surface (MJ m${ }^{-2}$ day $^{-1}$ ), $\mathrm{G}$ is soil heat flux density $\left(\mathrm{MJ} \mathrm{m}^{-2}\right.$ day $\left.^{-1}\right), \mathrm{T}$ is air temperature at $2 \mathrm{~m}$ height $\left({ }^{\circ} \mathrm{C}\right), \mathrm{u}_{2}$ is wind speed at $2 \mathrm{~m}$ height $\left(\mathrm{m} \mathrm{s} \mathrm{s}^{-1}\right), \mathrm{e}_{\mathrm{s}}$ is saturation vapour pressure $(\mathrm{kPa}), \mathrm{e}_{\mathrm{a}}$ is actual vapour pressure $(\mathrm{kPa}), \mathrm{e}_{\mathrm{s}}-\mathrm{e}_{\mathrm{a}}$ is saturation vapour pressure deficit $(\mathrm{kPa}), \Delta$ is slope vapour pressure curve $\left(\mathrm{kPa}^{\circ} \mathrm{C}^{-1}\right), \mathrm{Y}$ is psychometric constant $\left(\mathrm{kPa}^{\circ} \mathrm{C}^{-1}\right)$.

\section{Effective rainfall}

It is the part of rainfall which is stored in the soil profile and helps in the growing of crops. Rainfall of Dehradun district is depicted in table no. 2. To calculate the effective rainfall the USDA Soil Conservation Service method was used (Smith, 1991), using the following equations:-

$\mathrm{P}_{\text {eff }}=\mathrm{P}_{\text {tot }} \times\left(125-0.2 \mathrm{P}_{\text {tot }}\right) / 125 \quad$ for $\mathrm{P}_{\text {tot }}<$ $250^{\mathrm{mm}}$

$\mathrm{P}_{\text {eff }}=125+0.1 \times \mathrm{P}_{\text {tot }} \quad$ for $\mathrm{P}_{\text {tot }}>$ $250^{\mathrm{mm}}$

Where, $\mathrm{P}_{\text {eff }}$ represents effective rainfall $(\mathrm{mm})$ and $P_{\text {tot }}$ represents total rainfall $(\mathrm{mm})$

\section{Crop Evapotranspiration}

Crop coefficient approach is used by CROPWAT-8.0 Model for calculation of crop evapotranspiration and estimates by summing up the crop evapotranspiration in all growth stages, using the following equation:-

$\mathrm{ET}_{\text {crop }}=\mathrm{K}_{\mathrm{c}} \times \mathrm{ET}_{\mathrm{o}}$

Where, $\mathrm{ET}_{\mathrm{c}}$ represents crop evapotranspiration, $\mathrm{K}_{\mathrm{c}}$ represents crop coefficient and $\mathrm{ET}_{\mathrm{o}}$ represents reference evapotranspiration.

\section{Results and Discussion}

\section{Reference evapotranspiration}

The simulated values of reference evapotranspiration (ETo) through CROPWAT-8.0 model using PenmanMonteith equation along with the meteorological parameters for Dehradun district, is presented in table no. 1 and monthly distribution of Reference evapotranspiration is shown in the fig. 2 . From the result, it is revealed that the maximum $\mathrm{ET}_{0}$ was found high in the month of may $(5.28 \mathrm{~mm} /$ day), which is mainly due to high temperature and wind velocity, whereas it is minimum in the month of January (1.43 $\mathrm{mm} /$ day).

\section{Effective Rainfall}

The effective rainfall was calculated for the study area with the help of USDA, SCS method which is presented in table no. 2 and fig. no. 3. This will help for the estimation of irrigation water requirement of Rice crop for the same area. From the analysis, it is found that the maximum effective rainfall is in month of the July $(170.3 \mathrm{~mm})$ and minimum in the month of December $(22.3 \mathrm{~mm})$. 
Table.1 Reference evapotranspiration and meteorological parameters for the study area

\begin{tabular}{|c|c|c|c|c|c|c|c|}
\hline Month & Min Temp & Max Temp & Humidity & Wind & Sun & Rad & ETo \\
\hline & ${ }^{\circ} \mathbf{C}$ & ${ }^{\circ} \mathbf{C}$ & $\%$ & km/day & hours & MJ/m²/day & $\mathrm{mm} / \mathrm{day}$ \\
\hline Jan & 6 & 19.1 & 79 & 35 & 6.7 & 12.2 & 1.43 \\
\hline Feb & 8.1 & 21.3 & 69 & 52 & 7 & 14.6 & 2.02 \\
\hline Mar & 12.3 & 26.3 & 56 & 52 & 7.3 & 17.6 & 2.94 \\
\hline April & 17 & 32 & 40 & 69 & 8.6 & 21.6 & 4.36 \\
\hline May & 21.5 & 36.2 & 40 & 69 & 9.1 & 23.4 & 5.28 \\
\hline Jun & 23.6 & 35.2 & 55 & 52 & 7.2 & 20.9 & 4.87 \\
\hline Jul & 23.1 & 30.3 & 87 & 35 & 3.3 & 15 & 3.37 \\
\hline Aug & 22.7 & 29.5 & 91 & 35 & 2.9 & 13.6 & 2.98 \\
\hline Sept & 21.2 & 29.6 & 86 & 35 & 5.8 & 16.2 & 3.33 \\
\hline Oct & 16.1 & 28.2 & 76 & 52 & 8.4 & 17 & 3.1 \\
\hline Nov & 10.3 & 24.7 & 78 & 52 & 7.6 & 13.5 & 2.1 \\
\hline Dec & 7 & 20.8 & 80 & 35 & 7.1 & 11.9 & 1.47 \\
\hline Avg. & 15.7 & 27.8 & 70 & 48 & 6.8 & 16.4 & 3.1 \\
\hline
\end{tabular}

Source: New Loc-Clim Software

Table.2 Month-wise Rainfall (mm) and Effective rainfall (mm)

\begin{tabular}{|l|r|r|r|r|r|r|r|r|r|r|r|r|r|}
\hline Month & Jan & Feb & Mar & April & May & Jun & Jul & Aug & Sept & Oct & Nov & Dec & Total \\
\hline Rain (mm) & 60 & 43 & 67 & 27 & 54 & 161 & 453 & 445 & 248 & 108 & 29 & 23 & 1718 \\
\hline Eff rain (mm) & 54.2 & 40 & 59.8 & 25.8 & 49.3 & 119.5 & 170.3 & 169.5 & 149.6 & 89.3 & 27.7 & 22.2 & 977.3 \\
\hline
\end{tabular}

Table.3 Monthly water requirement of rice crop in Dehradun district

\begin{tabular}{|l|r|r|r|r|r|r|r|r|r|r|r|r|}
\hline Month & Jan & Feb & Mar & Apr & May & Jun & Jul & Aug & Sep & Oct & Nov & Dec \\
\hline Rice & 0 & 0 & 0 & 0 & 0 & 78.3 & 98 & 0 & 0 & 15.8 & 12.3 & 0 \\
\hline
\end{tabular}

Table.4 Net scheme irrigation required

\begin{tabular}{|c|c|c|c|c|c|c|c|c|c|c|c|c|}
\hline Net scheme irr.req. & Jan & Feb & Mar & Apr & May & Jun & Jul & Aug & Sep & Oct & Nov & Dec \\
\hline in $\mathbf{m m} /$ day & 0 & 0 & 0 & 0 & 0 & 2.6 & 3.2 & 0 & 0 & 0.5 & 0.4 & 0 \\
\hline in $\mathbf{m m} / \mathbf{m o n t h}$ & 0 & 0 & 0 & 0 & 0 & 78.3 & 98 & 0 & 0 & 15.8 & 12.3 & 0 \\
\hline in $\mathbf{l} / \mathbf{s} / \mathbf{h}$ & 0 & 0 & 0 & 0 & 0 & 0.3 & 0.37 & 0 & 0 & 0.06 & 0.05 & 0 \\
\hline
\end{tabular}

Table.5 Net scheme irrigation required

\begin{tabular}{|c|c|c|c|c|c|c|c|c|c|c|c|c|}
\hline Month & Jan & Feb & Mar & Apr & May & Jun & Jul & Aug & Sep & Oct & Nov & Dec \\
\hline Irrigated area $(\%)$ & 0 & 0 & 0 & 0 & 0 & 100 & 100 & 0 & 0 & 100 & 100 & 0 \\
\hline Actual area $(000 \mathrm{Ha})$ & 0 & 0 & 0 & 0 & 0 & 11.4 & 11.4 & 0 & 0 & 11.4 & 11.4 & 0 \\
\hline MCM & 0 & 0 & 0 & 0 & 0 & 8.9 & 11.2 & 0.0 & 0.0 & 1.8 & 1.4 & 0 \\
\hline
\end{tabular}


Table.6 Rainfall pattern of Dehradun district

\begin{tabular}{|c|c|c|c|c|c|}
\hline \multicolumn{5}{|c|}{ Average Rainfall (mm) } \\
\hline District & $\begin{array}{c}\text { SW monsoon } \\
\text { (June-Sep) }\end{array}$ & $\begin{array}{c}\text { NE Monsoon } \\
\text { (Oct-Dec) }\end{array}$ & $\begin{array}{c}\text { Winter } \\
\text { (Jan- March) }\end{array}$ & $\begin{array}{c}\text { Summer } \\
\text { (April-May) }\end{array}$ & Annual \\
\hline Dehradun & 1767.6 & 86.8 & 147.6 & 63.7 & 2065.7 \\
\hline
\end{tabular}

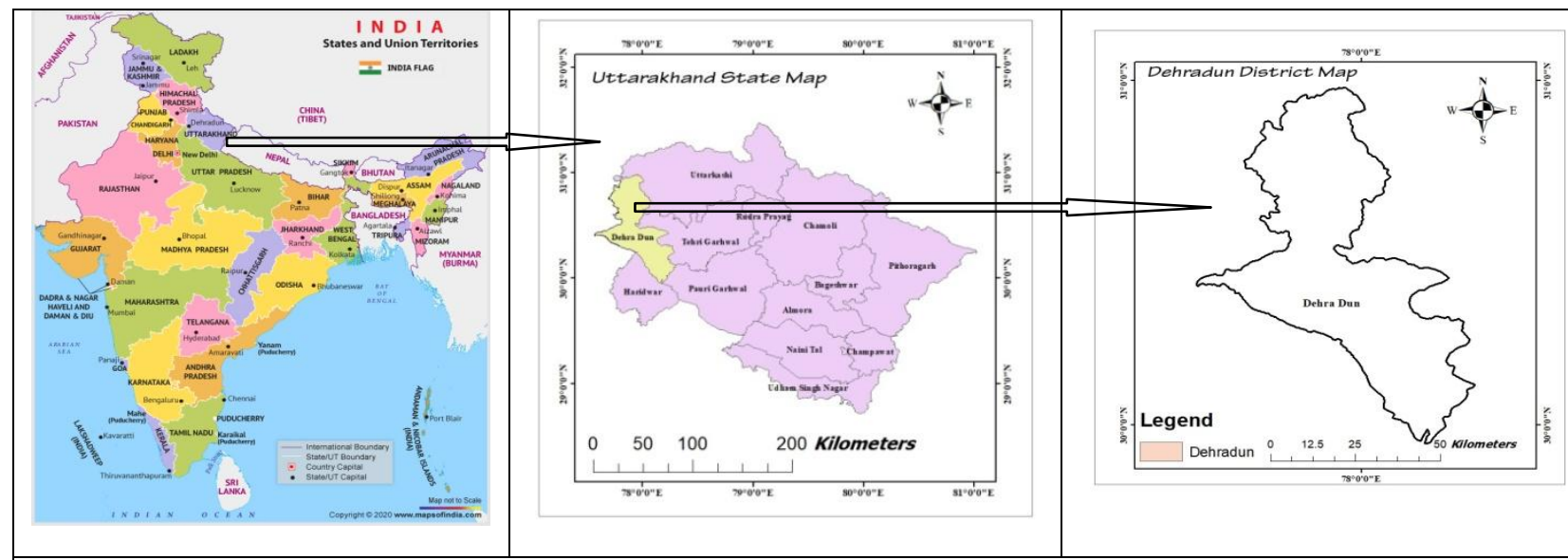

Fig.1 Location map of Dehradun District

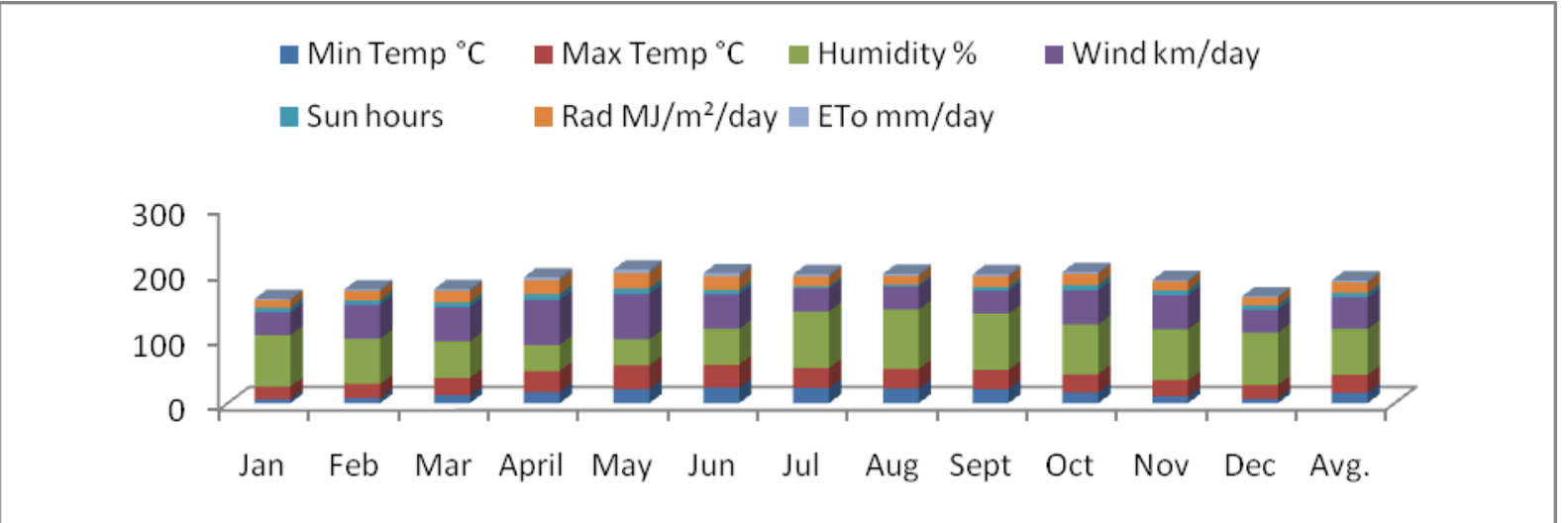

Fig.2 Monthly distribution of Reference evapotranspiration

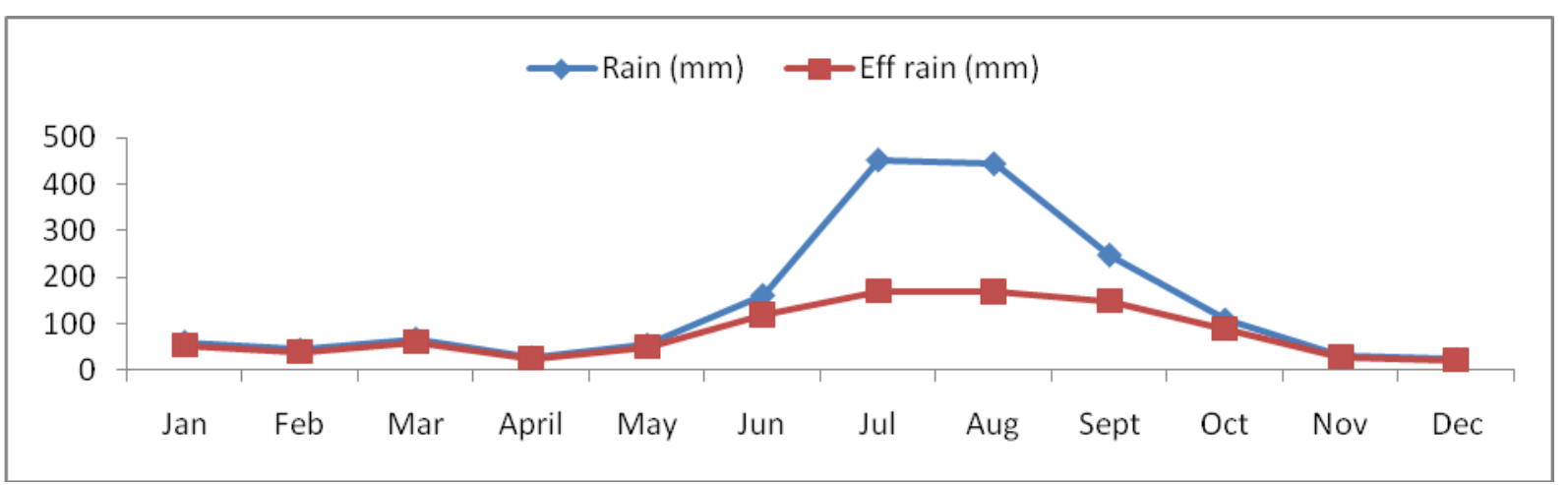

Fig.3 Month v/s Rainfall (mm) and Effective rainfall (mm) 


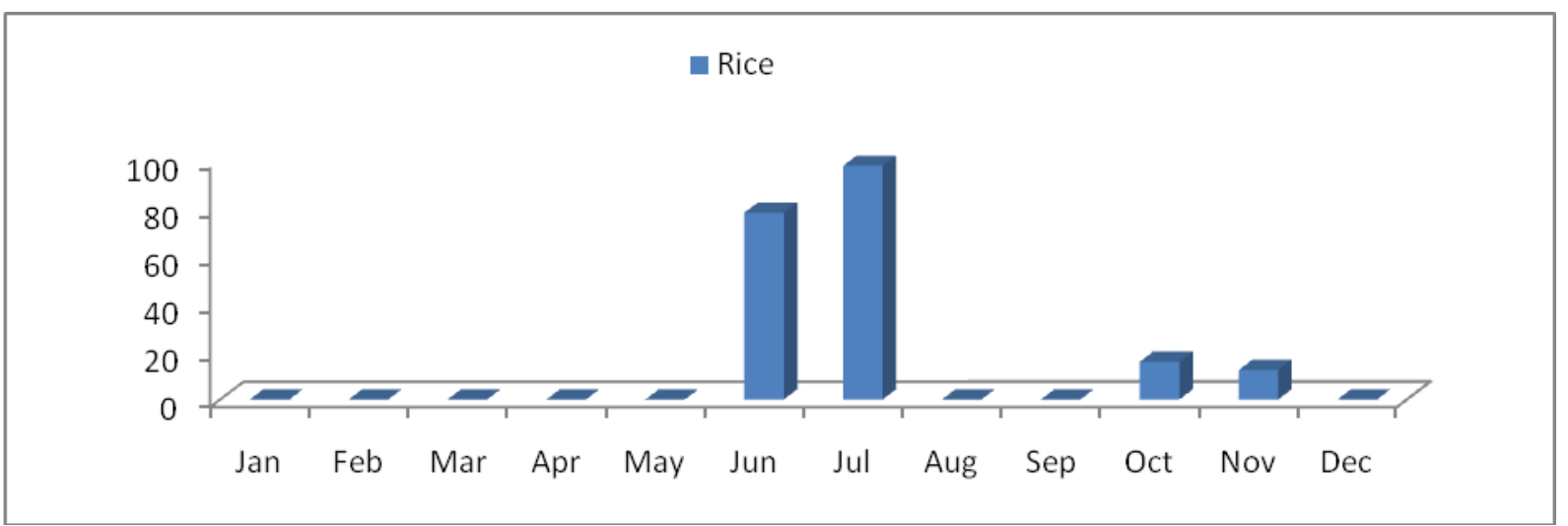

Fig.4 Month-wise crop water requirement of Rice Crop in Dehradun District

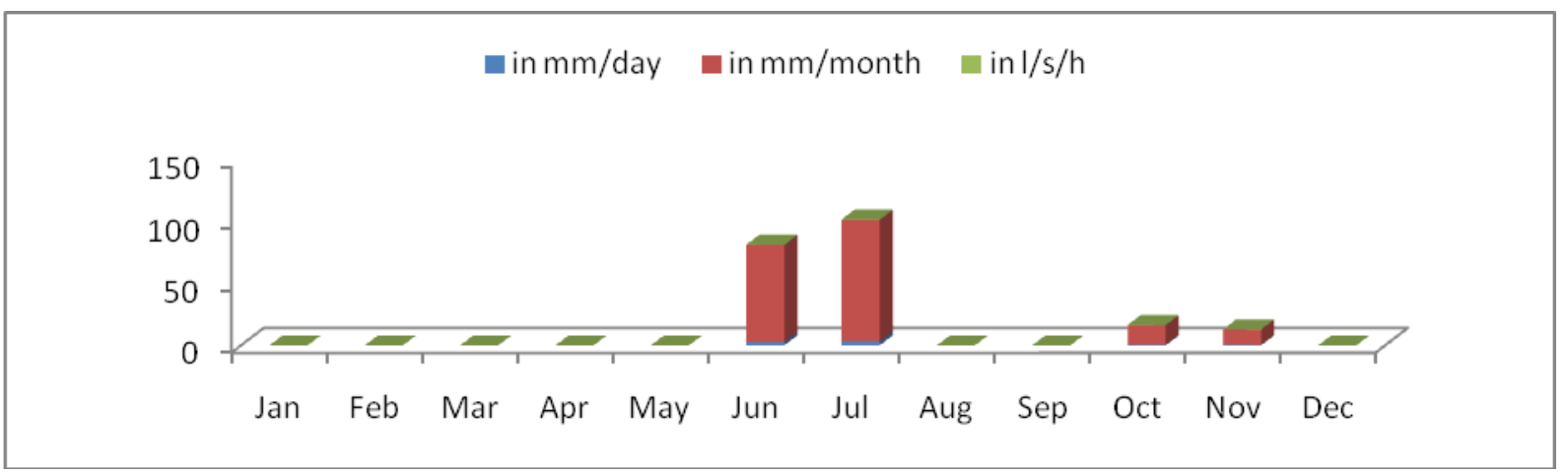

Fig.5 Net Scheme of Irrigation Required

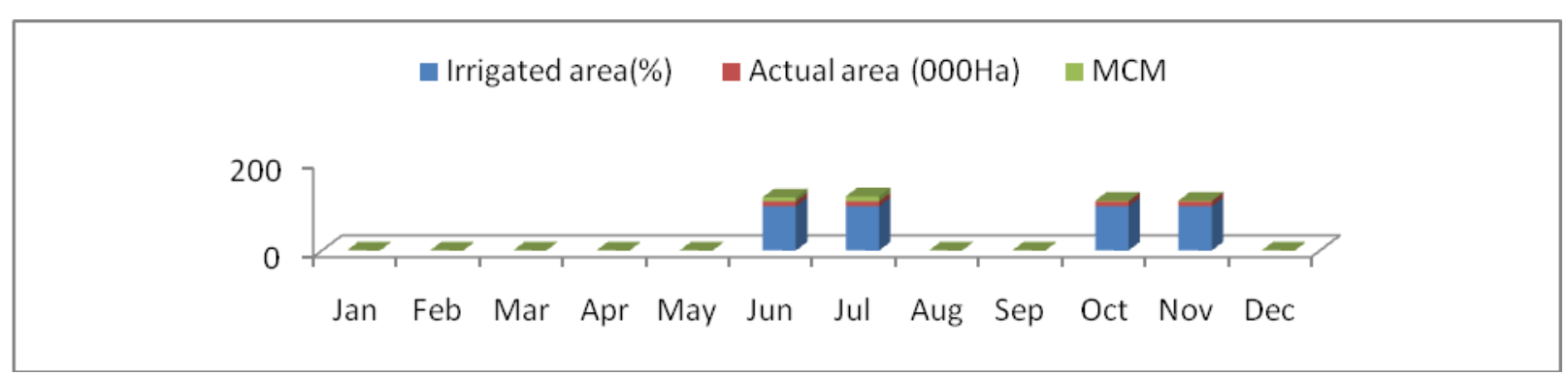

Fig.6 Net Scheme of Irrigation Required

\section{Crop Water Requirement}

The crop water need always refers to a crop grown under optimal conditions, i.e. a uniform crop, actively growing, completely shading the ground, free of diseases, and favourable soil conditions (including fertility and water). In simple form, the crop water need (ET crop) is defined as the depth (or amount) of water needed to meet the water loss through evapotranspiration. The water need is particularly function of the parameters as: - (i) the climate; in a sunny and hot climate crops need more water per day than in a cloudy and cool climate (ii) the crop type; crops like maize or sugarcane need more water than crops like millet or sorghum (iii) the growth stage of the crop; fully grown crops need more water than crops that have just been planted. Apart from sunshine and temperature, other climatic factors like wind velocity and humidity also influence the crop water need. Estimated Crop water requirement of Rice crop for Dehradun 
district in different months has been presented in table no. 3 and the water demand of crops presented in the fig 4 . The results show that the crop water requirement is more in the month of July followed by June month, for the study area, indicating high reference evapotranspiration in the same periods. This water demand for the crop will help in water management in the study area also assist in the scheduling of irrigation.

In conclusion, the research outcomes will provide a platform for efficient planning of water management and ultimately for increasing the water use efficiency. In other words, this research will help in the understanding the behaviour of weather parameter on reference evapotranspiration as well as in calculating net irrigation water requirement of rice crop in dehradun district.

\section{References}

Doorenbos, J. and Pruitt, W. O. 1976. Les Besoins en Eau des Cultures. Bull FAO Irrigation et Drainage, 24.

Doorenbos, J and Pruitt, W. O. 1977. Guidelines for predicting crop water requirements. FAO Irrigation and Drainage Paper 24.

Dechmi, F., Playan, E., Faci, J. M. 2003. Analysis of an irrigation district in northeastern Spain. Irrigation evaluation, simulation and scheduling. Agricultural Water Management, 61: 93-109.

FAO. 1977. Guidelines for predicting crop water requirements by J. Doorenbos and
W.O. Pruitt.

FAO Irrigation and Drainage Paper No. 24. Rome.

FAO, 1992. CROPWAT-8.0: A computer program for irrigation planning and management. FAO Irrigation and Drainage Paper 46. Rome: FAO, 126.

Gangwar A., Nayak T.R., Singh R.M. and Singh A. (2017). Estimation of crop water requirement using CROPWAT8.0 8.0 model for Bina command, Madhya Pradesh. Indian Journal of Ecology, 44(sp.4): 71-76.

Kar, G. and Verma, H.N. 2005. Climatic water balance, probable rainfall, rice crop water requirements and cold periods in AER 12.0 in India. Agricultural Water Management. 72: 15-32.

Kumar, T. 2005. Effect of organic sources on growth, yield and quality of potato.

Martyniak, L., Dabrowska, Z. K. and Szymczyk, R. 2006. Validation of satellite-derived soil vegetation indices for prognosis of spring cereals yield reduction under drought conditions Case study from central-western Poland. Advances in Space Research, 8: 1-6.

Surendran U., Sandeep O., Mammen George and Joseph E.J. 2013.A Novel technique of magnetic treatment of saline and hard water for irrigation

and its impact on cow pea growth and water properties.Int. J. Agri. Envt. and Biotech.6 (1) , 85-92.

\section{How to cite this article:}

Vikash Singh and Ramesh Verma. 2020. Prediction of Rice Water Requirement Using FAOCROPWAT-8.0 Model in Dehradun, Uttarakhand. Int.J.Curr.Microbiol.App.Sci. 9(02): 23062312. doi: https://doi.org/10.20546/ijcmas.2020.902.261 